\title{
0 apoio institucional e a produção de redes: do desassossego dos mapas vigentes na Saúde Coletiva
}

Michele de Freitas Faria de Vasconcelos ${ }^{1}$ Aline Morschel $^{2}$

\section{Introdução}

\begin{abstract}
De que valeria a obstinação do saber se ele assegurasse apenas a aquisição dos conhecimentos e não, de certa maneira, e tanto quanto possível, o descaminho daquele que conhece? Existem momentos na vida nos quais a questão de saber se se pode pensar diferentemente do que se pensa, e perceber diferentemente do que se vê, é indispensável para continuar a olhar ou a refletir. (Foucault, 2003a, p.13)
\end{abstract}

Este artigo foi pensado não como afirmação de uma idéia ou formulação de respostas a uma problemática, a um problema. Interessa-nos mais provocar deslocamentos. Pensamos, desde a nossa escrita e por meio dela, nos lançarmos na aventura de produzir formas compartilhadas de andares outros e de andar com outros. Nessas andanças, o objetivo é fazer novas conexões, compondo, como diria Cervantes (apud Vasconcelos, 2008), não uma paisagem de ilha, mas de encruzilhadas, ousando, inclusive, o descaminho.

Escrevemos "para fortalecer linhas de fuga nesses tempos em que a perturbação, essa potência de afetação que toda alteridade traz em seu seio se abranda ao ser inadvertidamente incluída, identificada, apaziguada" (Vasconcelos, 2008, p.188). Neste artigo, escrevemos para que análises sejam feitas, para que analisadores aconteçam, 'revelando' modos de funcionamento instituídos no campo da saúde coletiva, provocando-os, desestabilizando-os.

Inspirando-nos no movimento institucionalista (Lourau, 1995), entendemos o conceito-ferramenta "analisadores" como situações espontâneas ${ }^{3}$ ou produzidas que colocam algo (uma instituição, um dispositivo, uma encomenda) em análise. É o que, ao emergir em determinada situação - artificial ou espontânea -, possibilita uma quebra dos modos habituais, desestabilizando formas, muitas vezes, percebidas como naturais e até necessárias (Benevides, 2002; Coimbra, 2001). Apostamos, então, numa escrita que se faz para interferir, para perturbar o caráter de evidência dos saberes, fazeres, dos poderes e das sensibilidades que compõem esse cenário. Nele, por meio dele, atentas aos seus movimentos, vamos fiando um percurso, pensando a tessitura de redes de produção de saúde e na possibilidade de estas serem alinhavadas pelo apoio institucional.

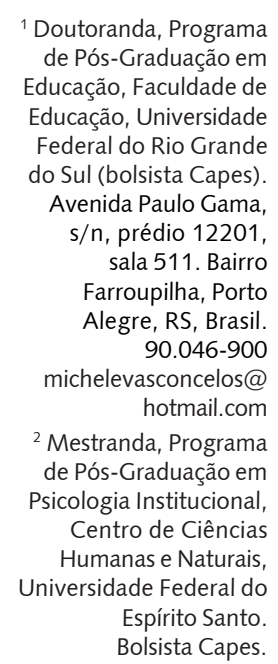
hotmail.com

${ }^{2}$ Mestranda, Programa de Pós-Graduação em Psicologia Institucional,

Centro de Ciências Humanas e Naturais, Universidade Federal do Espírito Santo. Bolsista Capes.

\footnotetext{
${ }^{3}$ Alguns autores têm trabalhado com o conceito de 'analisador histórico' ao invés de 'analisadores naturais' para tratar destas situações em que o analisador surge sem que seja intencionalmente construído ou artificialmente instalado. Rodrigues (2004, p.146), no entanto, problematiza esta mudança indagandonos se ela resolve a falta de clareza conceitual: “não seriam igualmente históricos os analisadores construídos?".
} 
Na perspectiva aqui apontada, entendemos que o objetivo central do apoio articula-se ao do analista institucional, qual seja: fomentar análises sobre a dinâmica de relações, de poderes, de práticas, de significações, de afetos que permeiam o estabelecimento analisado, colocando-as a serviço de todas as pessoas aí situadas, conferindo-lhes, assim, meios para pensarem sobre sua função e funcionamento, aliando-se a eles na análise dos ranços institucionais e problemas organizacionais e na subsequente abertura de sentidos, construção de redes e de práticas inéditas, discursivas e não-discursivas.

No sentido mesmo de subversão do instituído, mantendo-nos abertos ao irrepresentável e ao indizível, àquilo que está ainda por acontecer, o próprio nome "apoio institucional" deve ser posto em análise. Sua potência reside justamente no fato de ele localizar-se no "entre" das instituições, no "entre" dos estabelecimentos, no "entre" dos serviços, no "entre" atenção e gestão, no "entre" trabalhadores e usuários, no "entre" usuários inseridos nos serviços e usuários que encontramos fora dos espaços institucionais.

Conforme indica Lourau (2004), entende-se por instituição tanto um conjunto de normas, bem como o modo como os indivíduos se colocam em relação a estas. Trata-se de uma dimensão que perpassa tanto indivíduos, grupos formais e informais quanto organizações, não podendo ser identificada como um nível ou uma instância específica. Coimbra (2001, p.21-2) ressalta ainda que não é o estabelecimento ou local geográfico que denominamos de instituição, "mas relações e campos de força instituídos e produzidos", e que, justamente por este caráter de produção, pode ser analisada.

Em outras palavras, estamos tratando de um modo de pensar-fazer que circule por entre, na fronteira, nas margens dos saberes e das práticas institucionais, na zona de indeterminação que se produz entre eles. Isso porque entendemos que, nesse lugar de porosidade, é possível tratar o tema da saúde; mais ainda, é possível tratar da vida em sua complexidade. Estamos falando, enfim, de saberes e práticas que aceitam arriscar suas vidas a fim de se imiscuir na vida, de produzir vida, de impregnar e interferir concretamente na vida cotidiana, de atualizá-la (Vasconcelos, 2008).

\section{Saúde Coletiva: campo formado, em formação, formatado, conformado, desassossegado?}

Na contramão de perspectivas essencialistas e universalistas, que advogam a existência de uma origem, de uma essência, de uma identidade primeira para as coisas que compõem a 'realidade', Foucault (2003b, 2001) nos convida a pensar as gêneses como produções. Nesse mesmo sentido, afirma Coimbra (2001, p.38) que "a realidade - enquanto produção histórica [...] está sempre sendo construída por práticas sociais [...] as diferentes práticas vão engendrando no mundo objetos, sujeitos, saberes e verdades sempre diversos, sempre diferentes".

Colocar em análise o campo da saúde coletiva significa, então, desnaturalizá-lo. Significa entendê-lo como datado historicamente, forjando-se por meio de um agenciamento heterogêneo de intensidades (Deleuze, Guattari, 2000), as quais se localizam num espaço e num tempo específicos, e se dão perpassadas por relações de poder. O agenciamento funciona, assim, sempre a favor da produção, a qual se dá de modo simultâneo à sua própria formação.

Segundo Kastrup (2000), o conceito de agenciamento nos ajuda justamente a questionar a naturalização de um modo de pensar pautado em categorias modernas que colocam, por exemplo, de um lado, o sujeito e, do outro, o objeto, contextualizando-o e abrindo espaço para sua superação. Ainda para esta autora, "o encontro de fluxos heterogêneos não resulta na representação, mas na invenção de si e do mundo, sempre em transformação" (Kastrup, 2000, p.186).

Neste sentido, é preciso ter claro que não se trata da composição de paisagens estáveis, e sim de sequências cênicas instáveis, belicosas, atravessadas por lutas em torno da imposição de práticas, inclusive discursivas: "o discurso veicula e produz o poder; reforça-o, mas também o mina, expõe, debilita e permite barrá-lo" (Foucault, 2000, p.96). Ou seja, enquanto acontecimento, o discurso possibilita a irrupção de novos sentidos, de novas traduções. Em decorrência do poder que, por meio do discurso se exerce, este último é objeto de disputa, que tendo, como nos indica Foucault (2000, p.139), "suas regras de aparecimento e de circulação"; se coloca, já pela sua existência e não meramente pela sua aplicabilidade prática, como "objeto de uma luta e de uma luta política". Disso 
decorre a luta pelos sentidos que perpassam o campo da saúde coletiva, inclusive por sentidos atribuídos ao próprio nome 'saúde coletiva'.

Saúde coletiva, campo de conhecimento, campo teórico-metodológico, campo conceitual, campo de pesquisa, campo de práticas. Pesquisar e atuar neste campo, historicamente datado e marcado pela complexidade, exige o esforço de se evitarem simplificações reducionistas, cedendo lugar a formas de experimentação que indicam o desafio de se produzir conhecimento no encontro entre os saberes, no espaço de indeterminação entre as disciplinas, as metodologias e entre os objetos. Exige, sobretudo, um modo de operar que, ao invés de focalizar em objetos-alvo de certas teorias, disciplinas e metodologias, refira-se a práticas transversais e transdisciplinares (Vasconcelos, Barbosa, Morschel, 2007; Passos, Benevides, 2003; Almeida-Filho, 2000; Santos, 1995).

Sob que perspectiva(s) tal campo se constitui? Seguindo os rastros de Rodrigues (2000), perspectiva, aqui, não implica a idéia de uma miríade de olhares sobre uma realidade idêntica a si própria. Ela implica, sim, a produção de realidades e, nesse sentido, a própria produção do campo da saúde coletiva. Ou seriam campos, 'realidades' saúde coletiva? Formas de entendimento e de atuação variadas condensadas num mesmo nome?

Saúde coletiva, campo de dispersão. Campo de intensos confrontos que trazem consigo a possibilidade de abrir passagem para formas inusitadas de pensar e praticar saúde-doença-cuidado. Confrontos epistemológicos, metodológicos, entre disciplinas, entre saberes, políticos, sobretudo, micropolíticos.

Despindo-nos de concepções naturalizadas ou fundamentalistas; não nos restringindo aos muros das especialidades e espacialidades, eis que se anuncia a nossa perspectiva: antinormalizadora, desfocada da idéia de produção de verdades universais; um "transitar menor, produtivo, marcado por singularidades, por inventividade" (Lancetti, 2006, p.25).

\section{Habitando a babel Saúde Coletiva}

O que estamos propondo aqui é um modo de habitar o campo da saúde coletiva, um modo de fazer que, concebendo toda análise como contingente, despoja-se do desejo de apreender a essência de um dito objeto de intervenção ('a' saúde, 'o' humano, 'a' humanidade, 'o' coletivo) desvendando sua suposta identidade. Do mesmo modo, nos distanciamos da obstinação de propor 'o' Caminho para melhor abordá-lo ('a' política, 'o' modelo, 'o' método). Cabe aqui o desafio de estranhar nossos próprios domínios de referências e, com eles, problematizar a tendência a banalizar e naturalizar os próprios conceitosferramenta Coletivo e Humanização, dos quais temos nos servido para tentar produzir mudança de práticas.

Nesse sentido, a formulação de qualquer política, como, por exemplo, a

Aqui tomamos, como 'macro' desenvolvido por Deleuze e Guattari (1996), que diz respeito

não ao que é grande,

mas sim, concebendo-o como um sistema de referência caracterizado por segmentos que tendem à totalização e centralização. Ou seja,

trata-se de um sistema

duro distinto - porém coexistente - ao 'micro' que trata dos fluxos e das intensidades.
Política Nacional de Humanização (PNH), não é boa ou ruim em si. Há que se analisar os modos como ela vem sendo entendida, apropriada e o que tem disparado. É preciso que nos perguntemos, a todo instante, se o que estamos afirmando, partindo das indicações da $\mathrm{PNH}$, vem produzindo transformações nas posturas e práticas em saúde consoantes aos princípios colocados por esta, efetivando-se o compromisso ético-político de expansão da vida; ou se o uso que tem sido feito de tais indicações tem servido para maquiar, sob novos rótulos e dispositivos, lógicas de cuidado privatistas, especialistas e universalistas, justamente aquelas que pretendemos, com tal política, ultrapassar.

Muito se tem falado em direitos humanos, mas sob traduções molares, ou seja, mediante um aspecto 'macro' 4 , como expressão ou negação direta de um modelo 
unívoco de identidade, abarcando-se uma pluralidade de formas de viver e de conviver sob a categoria Humanidade. Sobre isso, Coimbra (2001) nos chama atenção para como a própria gênese dos direitos humanos, num entendimento capitalista hegemônico naturalizante e essencialista, determina de antemão quais os direitos a serem garantidos. Ainda segundo a autora supracitada, isto não apenas reforça um privilégio de uma determinada parcela da população, como a elite, bem como aponta uma compreensão em que não cabem as diferenciações, outros modos de sensibilidade e de existência, na medida em que a garantia dos direitos se dá condicionada ao que já se tem instituído como humano.

Respaldando-nos na categoria 'Humanidade', as diferenças/desigualdades tendem a não ser levadas em consideração ou, pelo menos, não lhes dão a devida atenção: diferenças de classe, de raça/cor, sexuais, de gênero, de religião etc. Ou seja, aquelas pessoas que costumam ser 'inseridas' nas redes formais de saúde tendem, ainda, a aparecer, de modo "unilateral e simplista", como "rostos" homogêneos, como "aqueles que têm um destino já conhecido e previsível" (Coimbra, 2001, p.250).

O convite que fazemos é, então, o de gaguejar em nossa própria língua, intentando a desnaturalização da 'realidade', dos objetos que nela existem, do humano, do sujeito, bem como do campo da saúde coletiva e dos modos de pensar e praticar saúde-doença-cuidado por ela propostos. O convite também é o de colocar problemas, estranhar o que parece óbvio, encarnar novas práticas, inclusive discursivas, de modo que aquilo que delas se estranhe, possibilite-nos a invenção de outras formas de viver, conviver, trabalhar, produzir, compondo outros cenários, subjetividades e cuidados em saúde.

Saliente-se, porém, que não estamos interessados na produção de diferenças 'quaisquer', que se dê em qualquer direção. Nosso trabalho tem um norte éticopolítico. Não nos esqueçamos de que o nascimento do que intitulamos de clínica dá-se, conforme salienta Lobosque (2003), justamente em instituições de disciplinamento, como os hospitais psiquiátricos, prisões, fábricas, objetivando a produtividade por meio de todo um "jogo econômico" que faz render a vida e a força dos corpos esquadrinhados. Assim, segundo a autora, há toda uma "vocação histórica" - inclusive da assistência em saúde -, em "fazer valer essas normas, disseminá-las socialmente ao torná-las aceitas incorporadas pelos indivíduos, culpabilizando e corrigindo aqueles que se desviam" (Lobosque, 2003, p.18).

É neste sentido, quer o saibam ou não, que a maioria dos profissionais de saúde tem empregado a palavra 'cuidado': articulando e subsumindo o objetivo de promover saúde à promoção do ajustamento social; de incluir ao de adaptar, normalizar, tornar igual, abolir a diferença.

Nessa direção é que o nosso compromisso ético-político incita o convite a gaguejar em nossa própria língua. Conforme aponta Goldman (2006, p.169):

Essa experiência e essa aliança com as linguagens estranhas pode estar a serviço de algo muito diferente [do que a simples identificação e governo das diferenças $]^{5}$, a saber, dessa contaminação positiva e criativa que toda linguagem sofre quando busca traduzir, ou se aliar, a outras linguagens - e é o que o autor brasileiro João Guimarães Rosa chama de 'fecundante corrupção das nossas formas idiomáticas de escrever'. [...]. No melhor dos casos, [...] essa questão assume a forma de um desafio que tem um cunho epistemológico, mas também ético e político: como proceder de modo a não reproduzir as relações de dominação a que os grupos sociais que estudamos se acham submetidos? 
Aqui o objetivo do apoio institucional vai começando a se desenhar. Mantendo viva a pergunta supracitada, a função apoio deve ser encarada, sobretudo, como um modo de produzir 'entre' linguagens, colocando a assistência prestada pelos 'peritos' em saúde, seus saberes e práticas, sob a crítica das idéias e práticas dos grupos 'assistidos' e, assim, abrindo-a à invenção.

E como se dá a invenção? Há como predizê-la, como antecipá-la? Ou será que, como não se podem produzir linhas de fuga porque elas estão aí, elas simplesmente acontecem, devemos espreitar o cotidiano dos espaços de produção de saúde e embarcar nessas linhas, fortificá-las? Nos espaços concretos, no vivido, no circunstancial, no local, logo ali onde a vida passa, onde a vida pulsa, à revelia de tentativas de aprisionamentos, homogeneizações, por entre engessamentos e burocratizações é que se dá a invenção, é que se dá a possibilidade dos deslocamentos. É justamente logo ali que se situa, à espreita, a potência do apoio institucional.

\section{Borrando mapas: colocando em análise o apoio institucional}

Como escrever senão sobre aquilo que não se sabe ou que se sabe mal? (Deleuze, 2006, p.18)

Retomando a nossa inquietação central, a saber, a idéia de movimento, ou melhor, o medo de que nossas práticas em saúde possam compor com o objetivo de burocratizar, constrangendo o movimento, o medo de assistir e de participar desse processo de institucionalização da saúde coletiva, da Política Nacional de Humanização, uma questão há que ser colocada: como interferir nesse processo a partir dos espaços que ocupamos, no cotidiano das redes de saúde, inseridas nela. Como resistir? E resistir implica necessariamente habitar esses espaços, movimentá-los, aquecê-los, produzir 'pequenas revoltas diárias' ao invés de sonhar com 'a' grande revolução (Veiga-Neto, 2001). Habitar os espaços, eis uma potência anunciada via apoio institucional.

Segundo as diretrizes propostas pela Política Nacional de Humanização (PNH), apoio é uma função gerencial que reformula o modo tradicional de se fazer coordenação, planejamento, supervisão e avaliação em saúde. É uma lógica, uma metodologia, por meio da qual se pretende desconstruir a idéia de que uma supervisão, um 'super-olhar', uma 'cabeça pensante' iria, do 'exterior' sem envolvimento com o espaço-tempo institucional, com o cotidiano dos serviços, prover os corpos executantes de respostas apuradas. Ao contrário, o apoio institucional tem como objetivo-chave justamente o de construir espaços de análise e interferência no cotidiano, potencializando análises coletivas de valores, saberes e fazeres e, desse modo, implementar e mudar práticas.

Optamos por falar e fazer interferência, em contraposição à noção de intervenção, isso porque esta última se articula a uma ação que se pretende completamente orientada por um objetivo preestabelecido. Interferir, antes, coloca-se como uma ação que não intenciona antecipar 'o' sentido que sua aproximação com o campo de relações construirá, abrindo espaço para deixar-se surpreender com tal campo e, nele, com os sentidos produzidos a partir de tal interferência (Altoé, 2004). Nesse sentido, anuncia-se a potencialidade da função apoio realizada a partir de uma implicação-inserção no cotidiano dos espaços de produção de saúde, de um olhar construído em conjunto com trabalhadores e usuários (Passos, 2006).

A partir das discussões de Araújo (2006, p.61-2), propomos pensar a função apoio institucional como a de um estrangeiro, trazendo a possibilidade de "borrar os mapas vigentes, cronificados" bem como "conceitos e métodos habituais". "O estrangeiro em si, estrangeiro no outro e o estrangeiro em nós (enquanto o ainda não-atualizado)" traz consigo a potência de perturbação ativada "através tanto daquilo que é quanto daquilo que pode fazer", isto é, "tanto por sua presença singular, quanto pelos universos do porvir que pode inventar, pelas forças que pode acionar na configuração de novos territórios existenciais, na afirmação de novos mundos".

"Como que lidando com um quebra-cabeça cuja imagem não é estática, as peças não são simétricas nem seu encaixe definido aprioristicamente" (Vasconcelos, 2008, p.14), em campo, por meio do campo, a função apoio institucional pede fluidez. Ela deve ser composta a partir de análises conjunturais, das particularidades de cada cenário, tendo-se como norte o objetivo de produzir marcas e caminhos sutis e singulares de acontecimentos que se entrecruzam formando redes. 
Rede se define aqui como "uma organização que é complexa, aberta, dispersa, sem centro unificador", e que tem como princípio a conectividade (Kastrup, 2000, p.17). Já os acontecimentos dos quais falamos se entrelaçam produzindo, como num rizoma, o campo de análise e interferência (Deleuze, Guattari, 2000). Vê-se, então, que o conceito de rede se aproxima do de rizoma, sendo este constituído por linhas, e não por pontos que o fazem crescer por meio de conexões múltiplas e que não obedecem uma organização hierárquica, não sendo ele mesmo uma estrutura, mas uma composição de fluxos variados, "um campo coletivo de forças dispersas, múltiplas e heterogêneas" (Kastrup, 2000, p.20).

Nessa direção, o apoio institucional pode ser entendido como um dispositivo de funcionamento em rede. Desse modo, os interstícios, os bastidores não devem ser ignorados, "eles estão presentes, atravessando, influenciando, transversalizando, enfim, as análises realizadas". O conceito "transversalização", central na Análise Institucional, entra em cena: refere-se justamente aos interstícios, aos "entrecruzamentos, pertenças e referências de todos os tipos que atravessam os sujeitos, os grupos, instituições e estabelecimentos", que nos atravessam, enfim (Coimbra, 2001, p.19).

Compondo com o que propõe a $\mathrm{PNH}$, entendemos que o apoio institucional abre a possibilidade de funcionar como articulador, como conector, produzindo novos territórios, borrando, embaralhando lugares previamente constituídos como aqueles convencionalmente denominados, identificados, dicotomizados como lugares de gestão e de atenção, de trabalhadores de saúde e de usuários. O apoio institucional se coloca aqui como um híbrido que, sem ponto de partida e de chegada, se faz em meio, no entre, nas margens, movimentando-se e pondo a movimentar os pontos conectados, potencializando a produção de redes quentes e não sectárias.

Mas afinal, de que rede falamos? A rede está dada? Ou será que se trata de pensarmos: que redes estamos pondo em funcionamento? Que redes estamos produzindo? Da mesma maneira que assinalamos a necessidade de escapar da insistência na procura das origens, aqui também pontuamos a importância de não idealizar onde chegar.

A aposta incide no fazer, no investimento em zonas problemáticas para as quais não encontramos respostas em nossos repertórios, nem mesmo em nossas cartilhas - ainda que estas nos forneçam pistas - arrancando-nos de nossas seguranças e nos impelindo a construir novos itinerários. Eis onde acreditamos se localizar a potência do apoio institucional: a possibilidade de atuar como intercessor, agenciar encontros e fomentar zonas de comunalidade.

Conforme Kastrup (2000, p.19), "a grafia do conceito deleuziano de intercessor segue a do verbo interceder, que significa intervir". Dessa forma, "produzir interferências não é o mesmo que fazer interseção, não significa meramente fazer um cruzamento entre dois conjuntos ou linhas - o importante aqui é que o cruzamento constitui uma zona de interferência". Já Pelbart (2003), inspirado em Hardt e Negri (2006), nos fala da comunalidade como essa produção do comum, da multidão, mas não como homogeneidade ou "pureza unitária" e essência perdida. Ao contrário, para o autor, e aqui para o que nos interessa em nossa aposta ético-política, pensamos as singularidades e os encontros que se fazem, pensamos na produção de "um comum" que é um "estar com", incidindo muito mais na potência do entre enquanto lugar virtual onde se "gestam novas modalidades de insubmissão, de rede, de contágio, de inteligência coletiva", onde se inscrevem as afetações, a produção de laços e a inventividade (Pelbart, 2003, p.84).

Partilhando, então, de uma perspectiva ético-político-afetiva e não tecnocrática, há que se registrar nossa implicação com a rede de saúde mental do município de Aracaju-Sergipe, desenhando algumas possibilidades e entraves que aí têm se colocado com relação à prática do apoio institucional.

Estamos falando de uma política, de práticas assistenciais, de dispositivos clínico-institucionais em construção, constituindo-se como campo de tensão, inclusive conceitual. E o que isso nos indica? A relevância de se fazer essa construção com base em nossas experiências concretas. Nesse sentido, os próprios conceitos só fazem sentido como conceitos-ferramenta, como ferramentas de trabalho, que nos auxiliem a organizar e executar nossas 'tarefas' (Foucault, 2001).

Nesse exato momento, estamos discutindo a função apoio institucional, uma função que, na rede de saúde mental aracajuana, compõe o coletivo gestor de saúde mental, de onde se desdobra o seguinte questionamento: como habitar o entre disciplinas, entre clínica e política, entre gestão e atenção, entre 
técnicos e usuários, entre saúde e outros setores sociais, entre Centro de Atenção Psicossocial (CAPS) e cidade? Como funcionar como intercessor/analista deste lugar de gestão? Como resistir à burocratização dessa função? Entre algumas saídas pensadas e experienciadas, destacamos justamente a produção e fortalecimento de espaços coletivos de gestão e de análise a respeito do cotidiano dos serviços de saúde mental e seus arredores.

Com o objetivo de funcionar como vírus-vida (Pelbart, 2003), de produzir redes quentes de discussão, trazer calor para espaços institucionalizados, compõe a agenda de trabalho dos apoiadores: o habitar assembléias com usuários, reuniões técnicas, reuniões de equipe de referência; o participar das festas, de visitas domiciliares, das reuniões do coletivo gestor de saúde mental; o produzir e fortalecer articulações entre os CAPS, com outros setores da saúde (atenção básica, DTS-Aids, rede de urgência e emergência, atenção hospitalar etc.), bem como parcerias intersetoriais (justiça, educação, cultura, trabalho etc.); o construir com trabalhadores e outros gestores espaços de educação permanente intra, inter e extra-CAPS; o discutir e fortalecer iniciativas de inovação clínico-institucionais, a exemplo de ações comunitárias, abordagens clínicas de rua, o acompanhamento terapêutico, as estratégias de redução de danos; o debater sobre outras diferenças/desigualdades (raça-cor, gênero, sexualidade, religião, classe) etc.

Em linhas gerais, a potência da função apoio institucional diz respeito à possibilidade de intercessão, articulação, interferência e produção de redes quentes de cuidado, discussão e análise do que tem sido produzido no cotidiano pelo coletivo de saúde mental (trabalhadores, usuários, comunidade, gestores). Tal interferência tem se desdobrado numa política de contágio e de articulação entre os CAPS, entre saúde mental e saúde, entre outros setores da sociedade e comunidades aracajuanas. Esta traz consigo a possibilidade de alargamento de respostas às demandas de saúde dos usuários e de trabalho dos trabalhadores/gestores, de fortalecimento da linha de cuidado e da (micro)política de saúde mental e de álcool e outras drogas. Acima de tudo, compõe a função apoio institucional problematizar a rede de saúde mental, o que contribui para torná-la quente, seguindo/produzindo movimentos, muitas vezes subterrâneos, comprometidos com a potência de vida, os quais acontecem no dia-a-dia de nossas práticas, solapando a burocratização e a mornidão, fazendo com que a discussão sobre saúde mental extravase dos muros dos CAPS e habite a cidade.

Em suma, ao invés de seguirmos obstinados a demonstrar um mundo dado ou um dado mundo, uma rede dada ou uma dada rede, os esforços devem objetivar a produção de mundos, de redes, de sentidos que nunca são antevistos nem muito menos previstos. Construção a posteriori por meio da qual se produzem narrativas cotidianas sobre as práticas cotidianas pelas quais a própria rede de saúde se constitui.

\section{Colaboradores}

Os autores trabalharam juntos em todas as etapas de produção do manuscrito. 


\section{Referências}

ALMEIDA-FILHO, N. A ciência da saúde. São Paulo: Hucitec, 2000.

ALTOÉ, S. (Org.). René Lourau: analista institucional em tempo integral. São Paulo: Hucitec, 2004.

ARAÚjO, G.B. Notas sobre uma clínica política. Cad. UFS -Psicol., v.8, n.3, p.57-66, 2006.

BENEVIDES, R.B. Saúde mental: a importância de se assegurarem direitos. In: RAUTER, C.; PASSOS, E.; BENEVIDES; R.B. (Orgs.). Clínica e política: subjetividade e violação dos direitos humanos. Rio de Janeiro: TeCorá, 2002. p.171-8.

COIMBRA, C. Operação rio: o mito das classes perigosas. Rio de Janeiro: Oficina do Autor, 2001.

DELEUZE, G. Diferença e repetição. 2.ed. Rio de Janeiro: Graal, 2006.

DELEUZE, G.; GUATTARI, F. Mil platôs: capitalismo e esquizofrenia. Rio de Janeiro: Editora 34, 2000. (Coleção TRANS, 1)

Mil platôs: capitalismo e esquizofrenia. Rio e janeiro: Editora 34, 1996. (Coleção TRANS, 3)

FOUCAULT, M. História da sexualidade II: o uso dos prazeres. 10.ed. Rio de Janeiro: Graal, 2003a.

A verdade e as formas jurídicas. 3.ed. Rio de Janeiro: NAU Editora, 2003b.

Microfísica do poder. 16.ed. Rio de Janeiro: Graal, 2001.

A arqueologia do saber. 5.ed. Rio de Janeiro: Forense Universitária, 2000.

GOLDMAN, M. Alteridade e experiência: antropologia e teoria etnográfica. Etnográfica, v.10, n.1, p.161-73, 2006.

HARDT, M.; NEGRI, A. Império. Rio de Janeiro: Editora Record, 2006.

KASTRUP, V. A psicologia na rede e novos intercessores. In: FONSECA, T.M.G.; FRANCISCO, D.J. (Orgs.). Formas de ser e habitar a contemporaneidade. Porto Alegre: Editora da UFRGS, 2000. p.13-26.

LANCETTI, A. A amizade e o acompanhamento terapêutico. In: SANTOS, R.G. (Org.). Textos, texturas e tessituras no acompanhamento terapêutico. São Paulo: Instituto A Casa/Hucitec, 2006. p.21-6.

LOBOSQUE, A.M. Clínica em movimento: por uma sociedade sem manicômios. Rio de Janeiro: Garamond, 2003.

LOURAU, R. Objeto e método da análise institucional. In: ALTOÉ, S. (Org.). René Lourau: analista institucional em tempo integral. São Paulo: Hucitec, 2004. p.66-86.

Análise institucional. Petrópolis: Vozes, 1995.

PASSOS, E. (Org.). Formação de apoiadores para a Política Nacional de Humanização da gestão e da atenção à saúde. Rio de Janeiro: Fiocruz, 2006. v.2.

PASSOS, E.; BENEVIDES, R.B. Complexidade, transdisciplinaridade e produção de subjetividade. In: FONSECA, T.M.G.; KIRST, P.G. (Orgs.). Cartografias e devires: a construção do presente. Porto Alegre: Editora da UFRGS, 2003. p.81-9. 
PELBART, P.P. Vida capital: ensaios de biopolítica. São Paulo: Iluminuras, 2003.

RODRIGUES, H.C. Análise institucional francesa e a transformação social: o tempo (e contratempo) das intervenções. In: RODRIGUES, H.C.; ALTOÉ, S. (Orgs.). Análise institucional: Saúdeloucura 8. São Paulo: Hucitec, 2004. p.115-64.

Construindo a história do institucionalismo no Brasil: linhas, modelos e ação. In: SEMINÁRIO DE HISTORIOGRAFIA DA PSICOLOGIA, 1., 2000, São Paulo. Anais... São Paulo: GEHPAI/FAPESP, 2000. p.49-80.

SANTOS, B.S. Um discurso sobre as ciências. 7.ed. Coimbra: Edições Afrontamento, 1995.

VASCONCELOS, M.F.F. Loucos e homossexuais: consumidores como outros quaisquer. Um estudo sobre modos de subjetivação de relações homoeróticas em um CAPS de Aracaju-SE. 2008. Dissertação (Mestrado) - Instituto de Saúde Coletiva. Universidade Federal da Bahia, Salvador. 2008.

VASCONCELOS, M.F.F.; BARBOSA, S.; MORSCHEL, A. Problematizando a saúde coletiva: produção de subjetividade no campo da saúde mental. Rev. Vivência, n.32, p.61-70, 2007.

VEIGA-NETO, A. Incluir para excluir. In: LARROSA, J.; SKLIAR, C. (Orgs.). Habitantes de babel: políticas e poéticas da diferença. Belo Horizonte: Autêntica, 2001. p.105-18. 
Ainda que perpassado por importantes consolidações teórico-práticas, o campo da saúde coletiva configura-se como campo em construção. Atentas a este campo e compondo com os movimentos que nele vão se fazendo, propomos neste artigo realizar um percurso discursivo, pensando a tessitura de redes de produção de saúde com base na função apoio institucional, mais especificamente, a partir de como tal função vem sendo experimentada na rede de Saúde Mental de Aracaju-Sergipe. De acordo com a Política Nacional de Humanização, o apoio institucional deve ser realizado a partir de uma implicação-inserção no cotidiano dos espaços de produção de saúde, de um olhar construído em conjunto com gestores, trabalhadores, usuários e comunidade. Alinhando-nos a tal perspectiva e aposta ético-política, pensamos a função apoio institucional como potente dispositivo de problematização de conceitos e métodos habituais, às vezes cronificados, da Saúde Coletiva, possibilitando novas articulações e produção de redes de saúde e cuidado.

Palavras-chave: Saúde Coletiva. Redes comunitárias. Apoio institucional.

Institutional support and network production: lack of tranquility in the current maps for public health

Although the field of public health has achieved important theoretical and practical consolidations, it remains under construction. Therefore, along with movements that will go on forming in this field, we propose a discursive approach for this paper, in order to consider the texture of healthcare production networks, starting from the institutional support function and, more specifically, from how this function has been experienced in the mental health network in Aracaju, Sergipe. According to the National Humanization Policy, institutional support should be given through implication and introduction of space within daily healthcare production, through a viewpoint constructed in conjunction with managers, workers, users and the community. In line with this perspective and the ethical and political bet, we envisage that the institutional support function will be a powerful device for questioning habitual (and sometimes chronic) concepts and methods within public health, thereby enabling new links and the production of healthcare networks.

Keywords: Public Health. Community network. Institutional support.

El apoyo institucional a la producción de redes:

del desasosiego de los mapas vigentes en la Salud Colectiva

Aunque cercano a importantes consolidaciones teórico-práctioas, el campo de la salud colectiva se configura como campo en construcción. En atención a este campo, y en conjunto con los movimientos que en él se van haciendo, proponemos en este artículo realizar un recorrido discursivo pensando la tesitura de redes de producción de salud a partir de la función del apoyo institucional; más especificamente, a partir del modo en que tal función se viene experimentando en la red de Salud Mental de Aracaju-Sergipe, Brasil. De acuedo con la Política Nacional de Humanización, el apoyo institucional ha de realizarse a partir de una implicación-inserción en el cotidiano de los espacios de producción de salud, de una mirada construida en conjunto con gestores, trabajadores, usuarios y comunidad. Aliándose a tal perspectiva y apuesta ético-política, pensamos la función apoyo instituoional como potente dispositivo de problematismo de conceptos y métodos habituales, de la Salud Colectiva hacendo posibles nuevas articulaciones y producción de redes de salud y cuidado.

Palabras clave: Salud Colectiva. Redes comunitarias. Apoyo institucional. 